\title{
Distribution of small proteoglycans and glycosaminoglycans in humerus-related articular cartilage of chickens
}

E.D. Rodrigues ${ }^{1}$, E.R. Pimentel ${ }^{2}$, P.A.S. Mourão ${ }^{3}$ and L. Gomes ${ }^{2}$

\section{Correspondence \\ L. Gomes \\ Departamento de Biologia Celular IB, UNICAMP \\ 13083-863 Campinas, SP \\ Brasil \\ Fax: +55-19-3788-6111 \\ E-mail: laure@unicamp.br}

Presented at the XI Congresso Brasileiro de Biologia Celular, Campinas, SP, Brazil, July 15-18, 2004.

Research supported by CNPq and FAPERJ. E.D. Rodrigues was the recipient of a PhD fellowship from FAPESP (No. 7/010204-8). $\ldots \ldots \ldots \ldots \ldots \ldots \ldots$

Received July 7, 2004 Accepted December 3, 2004

\author{
${ }^{1}$ Metabolic Research Unit and Diabetes Center, University of California, \\ San Francisco, CA, USA \\ ${ }^{2}$ Departamento de Biologia Celular, Universidade Estadual de Campinas, \\ Campinas, SP, Brasil \\ ${ }^{3}$ Laboratório do Tecido Conjuntivo, Hospital Universitário Clementino Fraga Filho \\ and Instituto de Bioquímica Médica, Centro de Ciências da Saúde, \\ Universidade Federal do Rio de Janeiro, Rio de Janeiro, RJ, Brasil
}

\begin{abstract}
The expression of components present in the cartilaginous extracellular matrix is related to development, gender, and genotype, as well as to the biomechanical properties of each type of cartilage. In the present study, we analyzed small proteoglycans and glycosaminoglycans present in different cartilages of the chicken wing after extraction with guanidine hydrochloride or papain. Quantitative analysis of glycosaminoglycans showed a larger amount in humeral cartilage (around 200 $\mathrm{mg} / \mathrm{g}$ tissue) than in articular cartilage of the radius and ulna, with 138 and $80 \mathrm{mg} / \mathrm{g}$ tissue, respectively. Non-collagenous proteins isolated were predominantly from cartilage in the proximal regions of the humerus and radius. D4 fractions obtained by ultracentrifugation were separated by DEAE-Sephacel and Octyl-Sepharose chromatography and analyzed by SDS-PAGE. Two bands of 57 and 70-90 kDa were observed for all samples treated with $\beta$-mercaptoethanol. Immunoblotting of these proteins was positive for the small proteoglycans fibromodulin and decorin, respectively. Apparently, the 57-kDa protein is present in macromolecular complexes of 160 and $200 \mathrm{kDa}$. Chondroitin sulfate was detected in all regions. HPLC analysis of the products formed by chondroitinase $\mathrm{AC}$ and $\mathrm{ABC}$ digestion mainly revealed $\beta$-D-glucuronic acid and $\mathrm{N}$-acetyl $\beta$-D-galactosamine residues. The 4-sulfation/6-sulfation ratio was close to 3 , except for the proximal cartilage of the radius (2.5). These results suggest functional differences between the scapula-humerus, humerus-ulna, and humerus-radius joints of the chicken wing. This study contributes to the understanding of the physiology of cartilage and joints of birds under different types of mechanical stress.
\end{abstract}

\section{Introduction}

Cartilage present in joints is a tissue adapted to offer resistance and to withstand different mechanical pressures in such a way as to facilitate articular movements (1). The extra-
Key words

- Proteoglycan

- Fibromodulin

- Decorin

- Glycosaminoglycan

- Cartilage

- Chicken cellular matrix present in articular cartilage, which consists of type II collagen, proteoglycans and other proteins, is associated with different biological processes, including the maintenance of biomechanical properties (2). The heterogeneity of cartilage is the result of 
morphological and biochemical variations between different regions that withstand diverse biomechanical forces (3), and that are characterized by different collagen arrangements and variations in glycosaminoglycan content (4). The relative amount and type of glycosaminoglycan varies according to the type of cartilage and its physiological and/or pathological state $(5,6)$.

Chondroitin sulfate is the predominant glycosaminoglycan in cartilage proteoglycans. It consists of repetitive disaccharides formed by glucuronic acid and N-acetyl Dgalactosamine residues, with a mean of one sulfate ester per disaccharide, which is bound to carbon 4 or 6 in the $\mathrm{N}$-acetyl hexosamine residue. Chondroitin 4-sulfate and 6-sulfate can be present in the same proteoglycan molecule. Variations in chain size, degree of sulfation and chondroitin 4-sulfate/6-sulfate ratio are associated with tissue physiology (7), age of the individual (8), and pathological state $(6,9)$.

The sulfation pattern of chondroitin sulfate in cartilage differs between embryos and adults. The presence of proteoglycans rich in chondroitin sulfate was initially detected in cartilage of chicken embryos (10), with a predominance of chondroitin 6-sulfate in the adult animal compared to the embryo (11). Chondroitin sulfate is the predominant glycosaminoglycan in the tibiotarsal and tarsometatarsal cartilage of chickens (Belline P and Gomes L, unpublished data), whereas dermatan sulfate and keratan sulfate are found in smaller quantities.

In cartilage, the predominant proteoglycan is a very large molecule known as agrecan, which contains chains of chondroitin sulfate and keratan sulfate. A class of small proteoglycans is also observed, which comprises a family of structurally related but genetically distinct molecules called small leucine-rich proteins (for a review, see Ref. 12). These low weight proteoglycans have also been detected in skin, tendons and sclera, and consist of a central protein, with decorin containing one chain and biglycan two chains of chondroitin sulfate or dermatan sulfate covalently linked to the N-terminal end (for a review, see Ref. 12). Another proteoglycan, denominated fibromodulin $(59 \mathrm{kDa})$, is found in articular cartilage and other tissues, and is characterized by the presence of four keratan sulfate chains in a central domain and various sulfated tyrosine residues in the N-terminal portion (13).

These small proteoglycans have the ability to interact with growth factors like tumor growth factor beta (TGF- $\beta$ ), which play an important role in the regulation of growth and cell differentiation. Fibromodulin and decorin are associated with regulatory functions of collagen fibrillogenesis, acting on the appropriate spacing of fibrils (14) and their axial growth, and also possibly participating in the lateral fusion of these molecules, as well as in in vitro and in vivo fibrillogenesis (for a review, see Ref. 12).

Articular cartilage represents an important model of a hierarchical biological structure, in which different components and levels of organization are responsible for the physiological efficiency of the joint (15).

In contrast to other joints, the compressive force seems to be lower in the scapulahumerus, humerus-ulna, and humerus-radius joints. These forces do not act in a uniform manner on the articular surfaces, especially when considering that the movements of the scapula-humerus joint differ from those of the humerus-ulna and humerus-radius joints.

Chickens can be affected by degenerative disorders of the joints and bone related to the normal development of the skeletal system. The prevention and control of these disorders in birds depends on the advances in the understanding of the physiological mechanisms that govern normal skeletal growth and of the biology of avian skeletal disorders (16). Few investigations have studied the cartilage of birds with respect to the biochemical composition of its extracellular matrix. Thus, the objective of the present 
study was to analyze the distribution of glycosaminoglycans and small proteoglycans present in different articular cartilage sites of the chicken wing.

\section{Material and Methods}

\section{Animals}

Groups of left and right wings $(\mathrm{N}=25)$ of 45-day-old broiler chickens (Hy-Line) killed by cervical dislocation were obtained from the local poultry industry. The articular cartilage was dissected, washed in PBS, dried, chopped, and kept at $-70^{\circ} \mathrm{C}$. The samples did not show distinctive degenerative signs or necrotic lesions and only articular interface regions were used. Figure 1 is a schematic drawing showing the skeletal components and cartilage sites used in this study: proximal humerus (Hp), distal humerus in contact with the radius (Hr), distal humerus in contact with the ulna $(\mathrm{Hu})$, proximal radius $(\mathrm{Rp})$, and proximal ulna (Up).

\section{Isolation of matrix components}

The cartilage samples were weighed, homogenized in PBS, $\mathrm{pH}$ 7.4, containing 150 $\mathrm{mM} \mathrm{NaCl}, 1 \mathrm{mM}$ PMSF and $20 \mathrm{mM}$ EDTA $\left(4^{\circ} \mathrm{C}\right)$ with a Polytron ${ }^{\mathrm{TM}}$ (Kinematica, Luzern, Switzerland) homogenizer, and centrifuged at $18,000 \mathrm{rpm}$ with a Beckman (Fullerton, CA, USA) JA-20 rotor. The precipitates were solubilized and then stirred for $24 \mathrm{~h}$ at $4^{\circ} \mathrm{C}$ with $4 \mathrm{M}$ guanidine- $\mathrm{HCl}$ in $50 \mathrm{mM}$ sodium acetate buffer, $\mathrm{pH} 5.8$, containing protease inhibitors, $1 \mathrm{mM}$ PMSF and $50 \mathrm{mM}$ EDTA (17). The extracts were separated from residual tissue by centrifugation using a Beckman JA-20 rotor at $20,000 \mathrm{rpm}$ and $4^{\circ} \mathrm{C}$ for 30 min.

The supernatants were adjusted to an initial density of $1.35 \mathrm{~g} / \mathrm{ml}$ with solid $\mathrm{CsCl}$. The solutions were then centrifuged in a Beckman centrifuge with an 80-Ti rotor at $34,000 \mathrm{rpm}$ and $15^{\circ} \mathrm{C}$ for $62 \mathrm{~h}$. The gradient was divided into four equal fractions (D1, D2, D3, and D4) (17). Only the D4 fraction, which contains the small proteoglycans, was used in the experiments.

\section{Analytical methods}

Protein (18), sulfated glycosaminoglycans (19), and hexuronic acid (20) were measured quantitatively using BSA, chondroitin sulfate and glucuronic acid as standards, respectively.

\section{Enzyme treatments}

Papain. Cartilage samples were kept in acetone at $4^{\circ} \mathrm{C}$ for $24 \mathrm{~h}$. The dry material $(0.5$ g) was treated with $50 \mathrm{mM}$ sodium acetate buffer, $\mathrm{pH} 5.5$, containing $0.5 \mathrm{~g}$ papain (15 $\mathrm{U} / \mathrm{mg}$ protein), $5 \mathrm{mM}$ EDTA, and $5 \mathrm{mM}$ cysteine (9). After $24-\mathrm{h}$ incubation at $60^{\circ} \mathrm{C}$, the samples were centrifuged and the supernatant was precipitated with 3 volumes of ethanol for $24 \mathrm{~h}$ at $1^{\circ} \mathrm{C}$. The precipitate was vacuum dried and dissolved in distilled water.

Chondroitinase. Glycosaminoglycans $(100 \mu \mathrm{g})$ were incubated at $37^{\circ} \mathrm{C}$ for $18 \mathrm{~h}$ in $50 \mathrm{mM}$ ethylenediamine/acetate buffer, $\mathrm{pH}$ 8.0, containing $0.01 \mathrm{U}$ chondroitinase $\mathrm{ABC}$ (EC 4.2.2.4) or ACII (EC 4.2.2.5) (21). The samples were then precipitated with ethanol, vacuum dried, and dissolved in Milli-Q grade water before HPLC. The disaccharides formed by the enzymes were analyzed by HPLC (see below) and the glycosaminoglycans resistant to digestion were checked by agarose gel electrophoresis.

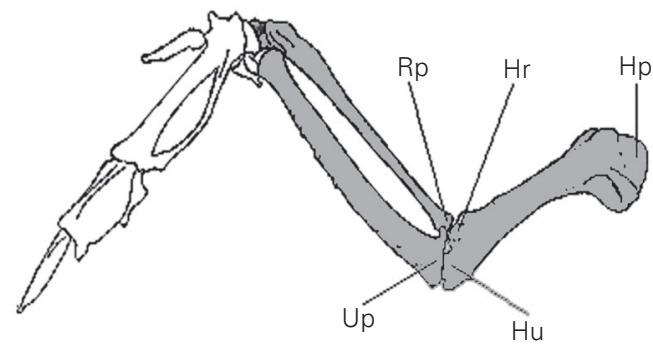

Figure 1. Schematic drawing indicating the anatomical regions of chicken wing cartilage used in this study. $\mathrm{Hp}=$ proximal humerus; $\mathrm{Hr}=$ distal humerus in contact with the radius; $\mathrm{Hu}=$ distal humerus in contact with the ulna; $R p=$ proximal radius; $U p=$ proximal ulna. 
lon-exchange and hydrophobic interaction chromatography

Fraction D4 obtained by ultracentrifugation was dialyzed three times in 30 volumes of $50 \mathrm{mM}$ Tris-acetate buffer, $\mathrm{pH} 8.0$, containing $7 \mathrm{M}$ urea. Aliquots containing $2 \mathrm{mg}$ protein were separated on a DEAE-Sephacel column (Amersham Pharmacia Biotech, Uppsala, Sweden) in the same buffer. Protein was eluted using a $0-1 \mathrm{M} \mathrm{NaCl}$ gradient and monitored by UV detection at $280 \mathrm{~nm}$. The protein fractions were analyzed by SDS-PAGE. Some fractions obtained by ion-exchange chromatography were pooled and dialyzed three times in 30 volumes of $50 \mathrm{mM}$ sodium acetate buffer, $\mathrm{pH}$ 6.3 , containing $2 \mathrm{M}$ guanidine-HCl. The material was applied to an Octyl-Sepharose column (Amersham Pharmacia Biotech) pre-equilibrated with the same dialysis buffer. After $4 \mathrm{~h}$, the material was eluted with a 2-6 M gradient of guanidine- $\mathrm{HCl}$ in $50 \mathrm{mM}$ sodium acetate buffer, $\mathrm{pH} 6.3$, and the eluate was analyzed by SDS-PAGE.

\section{HPLC}

The disaccharide content of papain/chondroitinase-treated samples described above

Figure 2. A, Hexuronic acid and sulfated glycosaminoglycan content of papain-treated tissue samples. Mean values are reported as $\mathrm{mg} / \mathrm{g}$ dry tissue. $B$, Protein, uronic acid, and sulfated glycosaminoglycan content of D4 fractions after centrifugation on a $\mathrm{CsCl}$ gradient. Mean values are reported as $\mathrm{mg} / \mathrm{ml}$ wet tissue. ANOVA with Fisher distribution $(P<0.05)$ indicated variability among means. $P=$ protein; $\mathrm{UA}=$ uronic acid; $\mathrm{GAG}=$ sulfated glycosaminoglycans. For abbreviations, see legend to Figure 1.

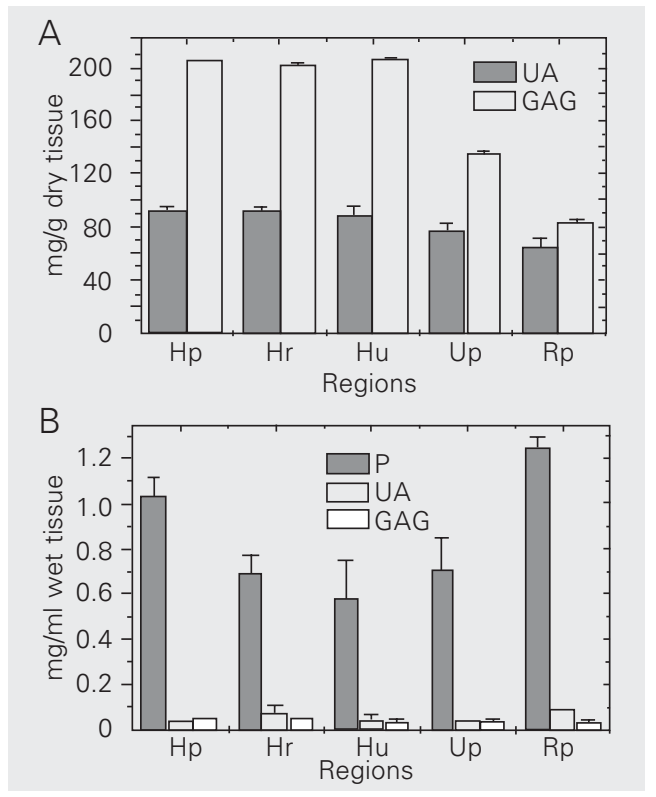

was analyzed by HPLC using a Supelco/ Spherisorb SAX column (Bellefonte, PA, USA). Elution was performed with a $0-1 \mathrm{M}$ $\mathrm{NaCl}$ gradient in water, $\mathrm{pH} 3.5(0.5 \mathrm{ml} / \mathrm{min})$, and monitored at $232 \mathrm{~nm}$.

\section{SDS-PAGE and immunoblotting}

Fractions obtained by ion-exchange and hydrophobic interaction chromatography were subjected to $4-16 \%$ SDS-PAGE (22) and stained by the silver method (23). Fractions obtained by hydrophobic interaction chromatography were transferred to a nitrocellulose membrane (24) and processed for indirect immunodetection using the following specific antibodies: rabbit Ig anti-chicken fibromodulin (diluted 1:20) and/or rabbit Ig anti-human decorin (diluted 1:100). The secondary antibody used was a swine horseradish-anti-rabbit Ig (diluted 1:500) and the reaction was developed with diaminobenzidine and $\mathrm{H}_{2} \mathrm{O}_{2}$.

\section{Agarose electrophoresis}

Glycosaminoglycans obtained after papain digestion were analyzed by $0.5 \%$ agarose gel electrophoresis with $50 \mathrm{mM} \mathrm{1,3-}$ diaminepropane/acetate buffer, $\mathrm{pH} 9.0$ (25). Chondroitin sulfate, dermatan sulfate, and heparan sulfate were used as standards. After electrophoresis ( $100 \mathrm{~V}$ for $1 \mathrm{~h})$, the material was fixed with $0.1 \%$ Cetavlon (N-cetyl$\mathrm{N}, \mathrm{N}, \mathrm{N}$-trimethylammonium bromide) and stained with $0.1 \%$ Toluidine blue.

\section{Statistical analysis}

Data were compared by one-way ANOVA with Fisher distribution, with the level of significance set at 5\% (26).

\section{Results}

Hexuronic acid and sulfated glycosaminoglycans were determined in solution after 
papain digestion of tissue (Figure 2A) and in D4 fraction (Figure 2B). In the former, a higher content of sulfated glycosaminoglycans was observed in the $\mathrm{Hp}, \mathrm{Hr}$ and $\mathrm{Hu}$ regions than in the Up and Rp regions. Up, on the other hand, accumulated more glycosaminoglycans than $\mathrm{Rp}$ (Figure 2A). The results of Figure 2A also suggest that $\mathrm{Up}$ and $\mathrm{Rp}$ regions may contain undersulfated glycosaminoglycans since the modification of hexuronic acid content was not as marked as the sulfated glycosaminoglycan concentration. This aspect requires further investigation.

Quantitative analysis of the D4 fraction (Figure 2B) showed more protein in Rp and $\mathrm{Hp}$ cartilages than in $\mathrm{Hu}$ and Up, with the latter not differing from one another. As expected, a very small amount of hexuronic acid and glycosaminoglycans was found in the D4 fraction of each sample.

The D4 fractions of the five cartilage regions were applied to DEAE-Sephacel, and most protein was eluted with a range of 0.2-0.4 M NaCl (data not shown). Samples of fractions eluted from the column were analyzed by SDS-PAGE (Figure 3). In the absence of B-mercaptoethanol, proteins of 160 and $200 \mathrm{kDa}$ were observed. A polydisperse component of 70-90 $\mathrm{kDa}$ was found under reducing and nonreducing conditions. In the presence of $\beta$-mercaptoethanol, the 160 - and $200-\mathrm{kDa}$ proteins were not detected, but a striking band appeared, corresponding to a protein of $57 \mathrm{kDa}$.

The fractions containing the 57- and 70to $90-\mathrm{kDa}$ proteins were pooled, subjected to Octyl-Sepharose chromatography and analyzed by gel electrophoresis (Figure 4A and $\mathrm{C}$, respectively). The $57-\mathrm{kDa}$ molecule was isolated and identified as fibromodulin by immunoblotting (Figure 4B). The process was unable to isolate the $70-$ to $90-\mathrm{kDa}$ molecules but immunoblotting using the antidecorin antibody was positive (Figure 4D).

Agarose gel electrophoresis of papaintreated samples revealed the presence of chondroitin sulfate showing slightly delayed

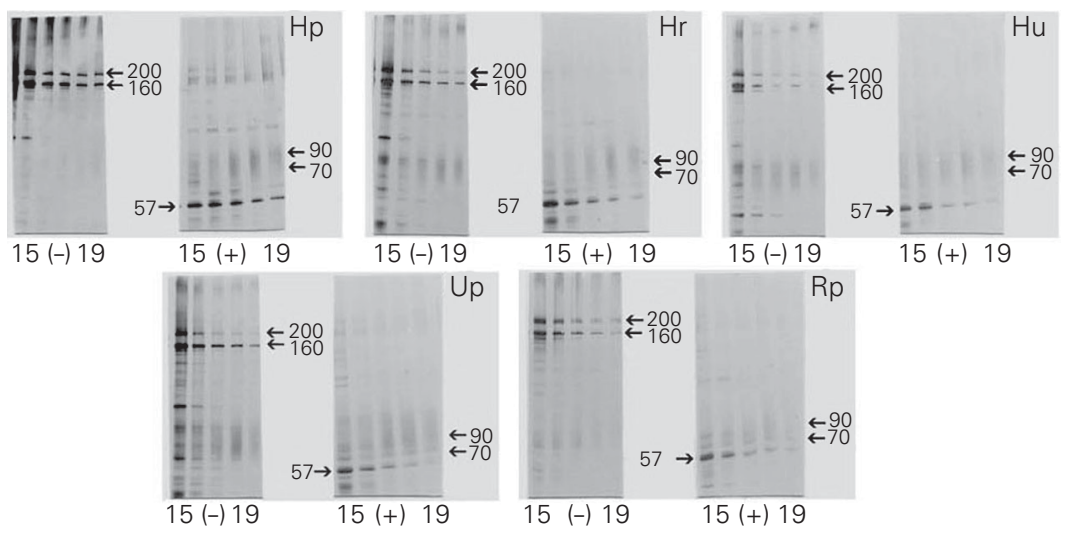

Figure 3. D4 fractions obtained from each region were separated by DEAE-Sephacel chromatography with $\mathrm{NaCl}$ gradient ranging from 0 to $1.0 \mathrm{M}$. The eluate was analyzed by SDS-PAGE. Two bands of 160 and $200 \mathrm{kDa}$ and a scattered band of 70-90 kDa were observed in the absence of $\beta$-mercaptoethanol (-). A $57-\mathrm{kDa}$ band was detected in the presence of $\beta$ mercaptoethanol $(+) . \mathrm{Hp}=$ proximal humerus; $\mathrm{Hr}=$ distal humerus in contact with the radius;

$\mathrm{Hu}=$ distal humerus in contact with the ulna; $U p=$ proximal $u l n a ; R p=$ proximal radius.
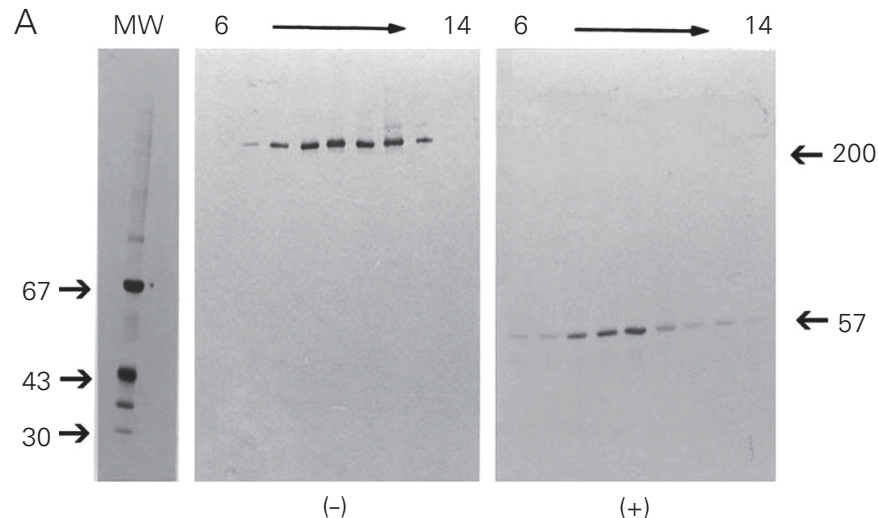

B
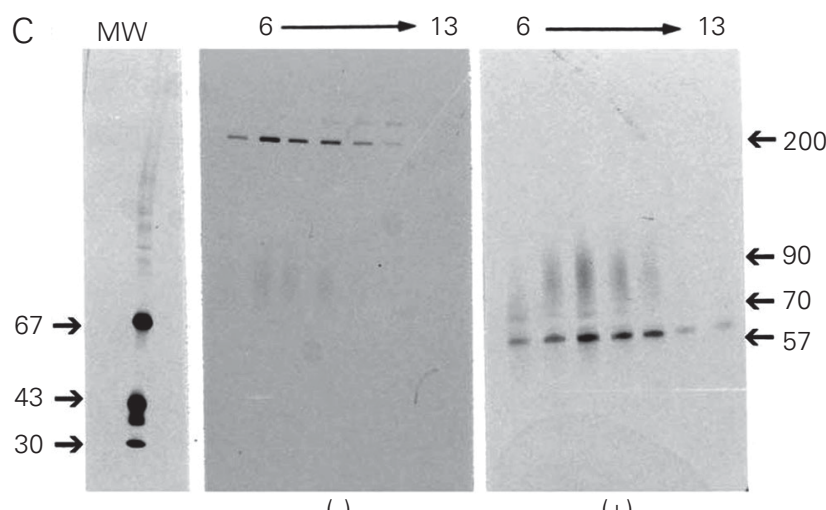

D

$(-)$

$(+$

Figure 4. The eluate obtained by Octyl-Sepharose chromatography was analyzed by SDS PAGE and immunoblotting to eventually characterize small proteoglycans of chicken wing cartilage. The D4 fraction from the region of the distal humerus in contact with the ulna was used but all regions showed the same pattern. A, SDS-PAGE showing the 200-kDa complex in the absence (-) of $\beta$-mercaptoethanol, which appears as a $57-\mathrm{kDa}$ component in the presence (+) of $ß-$ mercaptoethanol. $B$, The $57-\mathrm{kDa}$ molecule was identified as fibromodulin by immunoblotting. $C$, SDS-PAGE with eluates containing the $70-90-k D a$ component in the presence (+) and absence (-) of ß-mercaptoethanol, which was identified as decorin by immunoblotting (D). MW = molecular weight. 
electrophoretic mobility in all regions (Figure 5). No bands were detectable on agarose gels after treatment with chondroitinase $\mathrm{ABC}$ and ACII (data not shown).

The disaccharide content of glycosaminoglycans was analyzed by HPLC after enzymatic digestion with chondroitinase $\mathrm{ABC}$
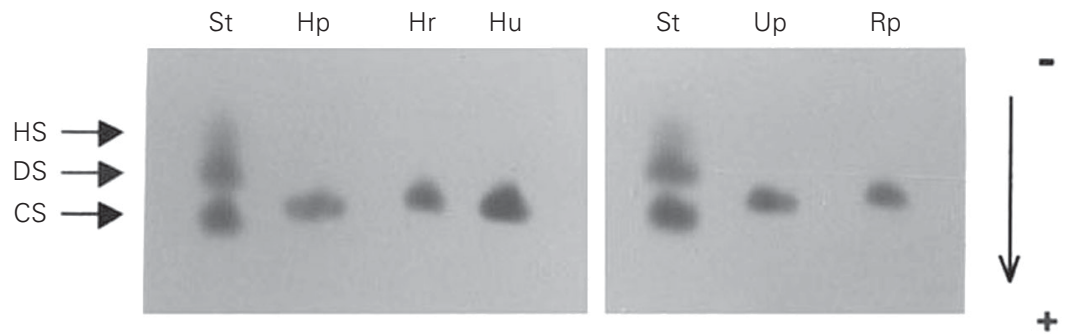

Figure 5. Analysis of glycosaminoglycans by propylenediamine agarose gel electrophoresis. Chondroitin sulfate is the main glycosaminoglycan. Standards (St) of chondroitin sulfate (CS), dermatan sulfate (DS), and heparan sulfate (HS) were used. The gel was stained with Toluidine blue. For other abbreviations, see legend to Figure 1.
(Figure 6). Chondroitin sulfate containing B$\mathrm{D}$-glucuronic acid and 4-sulfated $\mathrm{N}$-acetyl$ß$-D-galactosamine residues [GlcAß1-3Gal $\mathrm{NAc}\left(4 \mathrm{SO}_{3}\right)$ ] was present in all regions. The following disaccharides were obtained: $67 \%$ $\alpha$ - $\Delta$ UA- $1 \rightarrow 3$-GalNAc $\left(4 \mathrm{SO}_{4}\right)$ from chondroitin 4 -sulfate, $22 \% \quad \alpha-\Delta \mathrm{UA}-1 \rightarrow 3-$ GalNAc $\left(6 \mathrm{SO}_{4}\right)$ from chondroitin 6-sulfate, and $9 \% \quad \alpha-\Delta \mathrm{UA}-1 \rightarrow 3$-GalNAc from nonsulfated units (Table 1). Only traces of diand tri-sulfated disaccharides were formed ( $2 \%$ of the total). No difference was observed between the proportions of disaccharides formed by digestion with chondroitinase $\mathrm{ABC}$ and $\mathrm{ACII}$. This observation indicates that dermatan sulfate is not a component of the glycosaminoglycan mixture obtained from chicken cartilage. The ratio of 4sulfated:6-sulfated disaccharides was lower
Figure 6. HPLC analysis of disaccharides obtained after enzymatic digestion with chondroitinase $A B C$ using an anion-exchange Spherisorb-SAX column and $\mathrm{NaCl}$ gradient ranging from 0 to $1.0 \mathrm{M}$. The eluate was monitored at $232 \mathrm{~nm}$ and each region was analyzed separately. The numbered peaks correlate with the relative retention time of different disaccharide standards as follows: Peak 1, $\alpha$ $\triangle \mathrm{UA}-1 \rightarrow 3-G a l N A c ;$ Peak 2, $\alpha$ $\triangle \mathrm{UA}-1 \rightarrow 3-\mathrm{GaINAc}\left(6 \mathrm{SO}_{4}\right) ;$ Peak $3, \alpha-\Delta \cup A-1 \rightarrow 3-\mathrm{GaINAc}\left(4 \mathrm{SO}_{4}\right)$; Peak 4, $\alpha-\Delta \cup A-1 \rightarrow 3-$ GalNAc(2/ 6); Peak 5, $\alpha-\Delta \cup A-1 \rightarrow 3-G a l N A c$ $\left(4 / 6 \mathrm{SO}_{4}\right)$; Peak $6, \alpha-\Delta \cup A\left(2 \mathrm{SO}_{4}\right)-$ $1 \rightarrow 3-G a l N A c ;$ Peak $7, \alpha-\Delta \cup A$ $\left(2 \mathrm{SO}_{4}\right)-1 \rightarrow 3-\mathrm{GalNAc}\left(4,6 \mathrm{SO}_{4}\right)$. $\mathrm{Hp}=$ proximal humerus; $\mathrm{Hr}=$ distal humerus in contact with the radius; $\mathrm{Hu}=$ distal humerus in contact with the ulna; Up = proximal ulna; $\mathrm{Rp}=$ proximal radius.

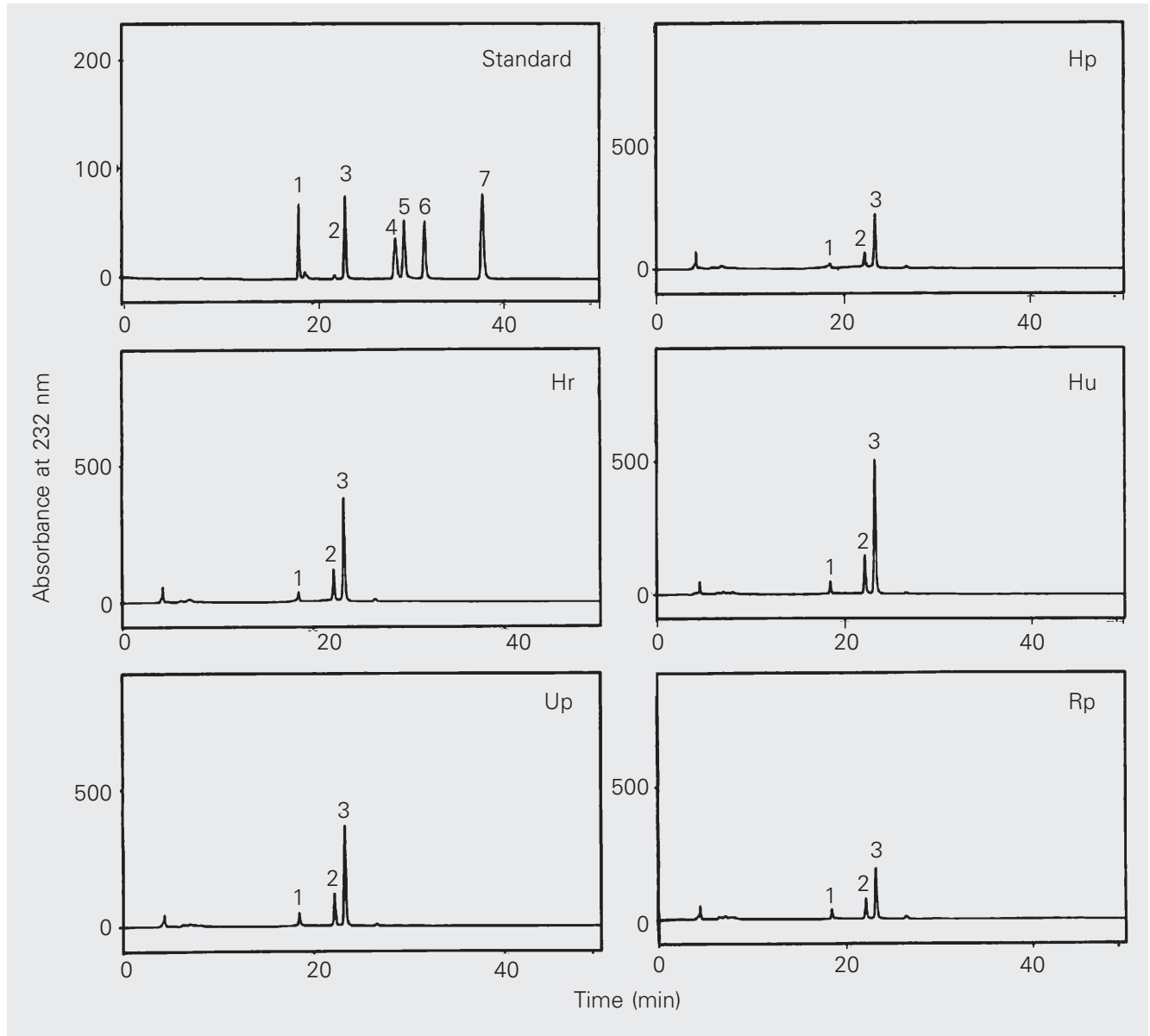


in the $\mathrm{Rp}$ region (2.51), while a ratio of 3 was observed in the other regions (Table 2).

\section{Discussion}

The physiological function of articular cartilage is to resist compression forces and to dissipate weight and movement forces applied to the joint. The organization and distribution of extracellular matrix components, as well as the integrity of this matrix, are fundamental for the maintenance of the tissue's biomechanical properties (27).

Commercially raised chicken can be affected by degenerative diseases of the joints that, among other consequences, lead to alterations in the distribution of proteoglycans in articular cartilage (28). In the present study, only regions which contact each other on the articular surface were used for analysis. Thus, the differences observed in hexuronic acid content and in sulfated glycosaminoglycans were determined by variations related to the physiological conditions present in each region depending on the nature and intensity of the biomechanical forces. Nakano and Sim (29) reported variations in chemical composition between the articular and subchondral cartilage of the chicken tibia. One aspect to be considered in these

Table 1. Analysis of the disaccharides formed by chondroitinase $A B C$ digestion of chondroitin sulfate from different regions of chicken wing cartilage.

\begin{tabular}{|c|c|c|c|c|c|c|c|}
\hline \multirow[t]{2}{*}{ Peak } & \multirow[t]{2}{*}{ Disaccharide } & \multirow[t]{2}{*}{$T(\min )$} & \multicolumn{5}{|c|}{ Total disaccharide (\%) } \\
\hline & & & $\mathrm{Hp}$ & $\mathrm{Hr}$ & $\mathrm{Hu}$ & Up & $\mathrm{Rp}$ \\
\hline 1 & $\alpha-\Delta \cup A-1 \rightarrow 3-G a l N A c$ & 18.5 & 10.4 & 8.2 & 8.0 & 9.2 & 10.5 \\
\hline 2 & $\alpha-\Delta \cup A-1 \rightarrow 3-G a I N A c\left(6 S_{4}\right)$ & 22.2 & 21.2 & 21.6 & 20.5 & 22.9 & 25.4 \\
\hline 3 & $\alpha-\Delta \cup A-1 \rightarrow 3-G a l N A c\left(4 S_{4}\right)$ & 23.4 & 67.1 & 69.5 & 71.3 & 67.6 & 63.6 \\
\hline 4 & $\alpha-\Delta \cup A\left(2 \mathrm{SO}_{4}\right)-1 \rightarrow 3-\mathrm{GalNAc}\left(6 \mathrm{SO}_{4}\right)$ & 28.7 & 28.7 & $<1$ & $<1$ & $<1$ & $<1$ \\
\hline 5 & $\alpha-\Delta \cup A-1 \rightarrow 3-G a l N A c\left(4,6-d_{i S O}\right)$ & 29.6 & 1 & $<1$ & $<1$ & $<1$ & $<1$ \\
\hline 6 & $\alpha-\Delta \cup A\left(2 \mathrm{SO}_{4}\right)-1 \rightarrow 3-\mathrm{GalNAc}\left(4 \mathrm{SO}_{4}\right)$ & 31.7 & $<1$ & - & - & - & - \\
\hline 7 & $\alpha-\Delta \cup A\left(2 S_{4}\right)-1 \rightarrow 3-G a I N A c\left(4,6-d_{i S O}\right)$ & 37.8 & $<1$ & - & - & - & - \\
\hline
\end{tabular}

$\mathrm{T}(\mathrm{min})$ represents the retention time in minutes of the disaccharides in the column. All regions showed a high concentration of $\alpha-\Delta \cup A-1 \rightarrow 3-G a I N A c\left(4 S_{4}\right)$ followed by $\alpha-\Delta \cup A-1 \rightarrow 3-G a I N A c\left(6 \mathrm{SO}_{4}\right)$ and $\alpha-\Delta \cup A-1 \rightarrow 3-G a I N A c$. $\mathrm{Hp}=$ proximal humerus; $\mathrm{Hr}=$ distal humerus in contact with the radius; $\mathrm{Hu}=$ distal humerus in contact with the ulna; $U p=$ proximal ulna; $R p=$ proximal radius; $\alpha-\Delta U A=4$-deoxy- $\alpha$-L-threo-hex-4-enopyranosyluronic acid; $\alpha-\Delta \cup A\left(2 \mathrm{SO}_{4}\right)=$ an $\alpha-\Delta \cup A$ derivative bearing a sulfate ester at position 2; GalNAc $=N$-acetylated galactosamine; GalNAc $\left(6 \mathrm{SO}_{4}\right), \mathrm{GalNAc}\left(4 \mathrm{SO}_{4}\right)$ and $\mathrm{GalNAc}\left(4,6-\mathrm{diSO}_{4}\right)$ are GalNAc derivatives bearing a sulfate ester at position 6 , position 4 or at both positions, respectively. The disaccharide $\alpha-\Delta \cup A-1 \rightarrow 3-G l c N A c$, originating from hyaluronic acid, was not detected $(<2 \%$ of the total products formed by chondroitinase ACll digestion).

Table 2. Proportions and ratios of 4-sulfated and 6-sulfated disaccharide units in chondroitin sulfate from different regions of chicken wing cartilage.

\begin{tabular}{llllll}
\hline \multirow{2}{*}{ Component } & \multicolumn{5}{c}{ Cartilage region } \\
\cline { 2 - 6 } & $\mathrm{Hp}$ & $\mathrm{Hr}$ & $\mathrm{Hu}$ & $\mathrm{Up}$ & $\mathrm{Rp}$ \\
\hline$\alpha-\Delta \mathrm{UA}-1 \rightarrow 3-\mathrm{GaINAc}\left(4 \mathrm{SO}_{4}\right)$ & 7.52 & 8.55 & 8.98 & 7.17 & 6.06 \\
$\alpha-\Delta \cup \mathrm{U}-1 \rightarrow 3-\mathrm{GaINAc}\left(6 \mathrm{SO}_{4}\right)$ & 2.42 & 2.64 & 2.58 & 2.43 & 2.41 \\
Ratio 4S:6S & 3.1 & 3.23 & 3.48 & 2.95 & 2.51 \\
\hline
\end{tabular}

For abbreviations, see legend to Table 1. 
differences is the type of movement itself. In the scapula-humerus joint the movement is triaxial, while in the humerus-ulna and humerus-radius joints the movement is uniaxial, conferring different biomechanical properties to these joints.

The study of cartilage proteoglycans in different anatomical regions and different models, such as the bovine distal femoral epiphysis (30), bovine metacarpophalangeal joint (31), rabbit and dog joints (32), and xiphoid cartilage (33), has demonstrated variations in the composition and distribution of proteoglycans.

In the present study, two proteins of approximately 160 and $200 \mathrm{kDa}$ were detected in the different articular cartilage regions of the chicken wing analyzed. In the presence of the reducing agent, these bands became weak, with the appearance of a $57-\mathrm{kDa}$ band and a migration pattern similar to that of fibromodulin. These results are similar to those reported by Gomes et al. (34) for the chicken tibiotarsal-tarsometatarsal joint, showing that a $250-\mathrm{kDa}$ complex migrates with an $\mathrm{Mr}$ of $59 \mathrm{kDa}$ under reducing conditions on SDS-PAGE. A meniscus exists in these joints which permits a better load distribution per $\mu \mathrm{m}^{2}$ surface. In the wing joints, the compressive force is very low, with shearing forces predominating. Curiously, protein aggregates can be observed in these joints, which show a $57-\mathrm{kDa}$ band under reducing conditions, identified as fibromodulin by immunoblotting. Bidanset et al. (35) demonstrated that decorin, biglycan and fibromodulin can bind to collagen type VI through the protein core, especially in the leucine-rich sequence. A similar interaction probably occurs between these small proteoglycans and elements of the extracellular matrix, since Roughley and White (36) demonstrated that independent migration between dermatan sulfate proteoglycans and aggregating proteoglycans only occurs in the presence of SDS and $\beta$-mercaptoethanol.

Possible interactions between small pro- teoglycans and collagen molecules or among small proteoglycans themselves as a result of self-aggregation do not depend on interchain disulfide bridges. However, the maintenance of disulfide bridges in the protein core of small proteoglycans is important to maintain the conformation of these molecules, favoring interaction processes.

Although there are indications that fibromodulin, in addition to aggrecan, appears more intensely in tissues under compression (33), our results show that fibromodulin is also present in tissues submitted to low compression, as observed for the bird wing joint. In this case, fibromodulin appears in an aggregated state not due to disulfide bridges but dependent on the preservation of intramolecular disulfide bridges.

In all regions, a component that appeared as a polydisperse band with an $\mathrm{Mr}$ of 70 to 90 $\mathrm{kDa}$ was observed. This molecule was less concentrated in the $\mathrm{Rp}$ region. The presence of ß-mercaptoethanol did not alter its electrophoretic profile, which was similar to that of decorin. Immunoblotting revealed that the component with an $\mathrm{Mr}$ of $70-90 \mathrm{kDa}$ was in fact decorin.

The sulfated glycosaminoglycans of the cartilage regions analyzed here showed a slightly delayed electrophoretic mobility compared to the chondroitin sulfate standard, suggesting a differentiated sulfation pattern for this chondroitin sulfate as observed for the dermatan sulfate of ascidians (37). In addition to the level of sulfation, the size of the glycosaminoglycan chains can influence migration. This slow migration of chondroitin sulfate was also observed in the cartilage of the chicken tibiotarsus and tarsometatarsus (Belline P, personal communication).

Based on the relative proportions of disaccharides formed by chondroitinase $\mathrm{ABC}$ and ACII digestion and on the content of hexuronic acid, it is possible to calculate the absolute concentration of chondroitin 4-sulfate and chondroitin 6-sulfate in cartilage. 
The only difference between these disaccharides is that they are epimeres of the hexosamine portion of the molecule, a fact impairing their separation (38). In humans, articular cartilage and intervertebral discs contain an average of $82 \%$ chondroitin 6 -sulfate and $18 \%$ chondroitin 4 -sulfate, while the subarticular cartilage of different regions contains an average of 55\% chondroitin 4sulfate and $45 \%$ chondroitin 6 -sulfate (5).

In the present study, the products formed by chondroitinase digestion indicated a preponderance of $\beta-\mathrm{D}$-glucuronic acid and 4-Osulfated $\mathrm{N}$-acetyl- $\beta$-D-galactosamine residues in the chondroitin sulfate present in the different cartilage regions. The main disaccharides in chicken chondroitin sulfate are GlcA-1 $\rightarrow 3$-GalNAc( $\left.4 \mathrm{SO}_{4}\right)(\sim 67 \%)$, a derivative of chondroitin 4-sulfate, followed by GlcA-1 $\rightarrow 3$-GalNAc $\left(6 \mathrm{SO}_{4}\right)(\sim 22 \%)$, a derivative of chondroitin 6-sulfate, and GlcA-1 $\rightarrow 3$ GalNAc ( $\sim 9 \%)$ from non-sulfated units. Only traces of di- and tri-sulfated disaccharides were formed, corresponding to $2 \%$ of the total obtained. Therefore, the predominant sulfation in all cartilage regions used in our study was at position 4 . A lower $\Delta$ Di- $4 \mathrm{~S} /$ $\Delta$ Di-6S ratio (2.51) was observed in the region of the proximal cartilage of the radius, while all other regions showed ratios of about 3 .

The distribution of glycosaminoglycans in cartilage is species specific and highly variable. In humans (5) and dogs (7), the presence of chondroitin 4-sulfate in cartilage of young growing individuals, which disappears after calcification in adults, suggests that this glycosaminoglycan is one of the extracellular matrix components important for calcification processes, whereas chondroitin 6-sulfate is responsible for the integrity of articular cartilage, playing a secondary role in calcification processes. The relative proportions of chondroitin 4-sulfate and chondroitin 6-sulfate change with age and during arthritic processes $(6,9)$.

In addition to providing further knowledge about the extracellular matrix composition of the articular cartilage of birds, the present results show the existence of a higher ratio of chondroitin 4-sulfate to chondroitin 6-sulfate in cartilage subjected to lower compressive force, which might be related to the biomechanical properties of the wing joints analyzed. The mechanical action exerted on the wing joints during flight is less compressive compared to that of other joints such as the knee and hip, where the load on the articular surfaces is high. Comparative studies between the analog joints of humans and birds performed by Barnet (39) have revealed anatomicophysiological similarities despite the phylogenetic distance.

\section{References}

1. Buckwalter JA \& Mankin HJ (1997). Articular cartilage. Journal of Bone and Joint Surgery, 79-A: 600-611.

2. Heinegård D \& Oldeberg A (1989). Structure and biology of cartilage and bone matrix noncollagenous macromolecules. FASEB Journal, 3: 2042-2051

3. Bullough PG, Yawitz PS, Tafa L \& Boshey Al (1985). Topographical variations in the morphology and biochemistry of adult canine tibial plateau articular cartilage. Journal of Orthopaedical Research, 3: 116

4. Simon WH (1970). Scale effects in animal joints. I. Articular cartilage thickness and compressive stress. Arthritis and Rheumatism, 13: 244-255

5. Mourão PAS, Rozenfeld S, Laredo J \& Dietrich CP (1976). The distribution of chondroitin sulfates in articular and growth cartilages of human bones. Biochimica et Biophysica Acta, 428: $19-26$.

6. Mourão PAS, Michelacci YM \& Toledo OMS (1979). Glycosaminoglycan and proteoglycan of normal and tumoral cartilages of human and rats. Cancer Research, 39: 2802-2806.

7. Harab RC \& Mourão PAS (1989). Increase of chondroitin 4-sulfate concentration in the endochondral ossification cartilage of normal dogs. Biochimica et Biophysica Acta, 992: 237-240.

8. Heise N \& Toledo OMS (1993). Age-related changes in glycosaminoglycans distribution in different anatomical sites on the surface of knee-joint articular cartilage in young rabbits. Annals of Anatomy, 175: $35-40$

9. Michelacci YM, Mourão PAS, Laredo J \& Dietrich CP (1979). Chondroitin sulfates and proteoglycans from normal and arthrosic human cartilage. Connective Tissue Research, 7: 29-36. 
10. Kitamura K \& Yamagata $T$ (1976). The occurrence of a new type of proteochondroitin sulfate in the developing chick embryo. FEBS Letters, 71: 337-340.

11. Shulman HJ \& Meyer K (1970). Keratan sulfate-containing proteinpolysaccharide of chicken cartilage and chondrocyte cell cultures. Federation Proceedings, 29: 928-934.

12. Iozzo RV (1998). Matrix proteoglycans: from molecular design to cellular function. Annual Review of Biochemistry, 67: 609-652.

13. Oldberg A, Antonsson $P$, Lindblom K \& Heinegård $D$ (1989). A collagen-binding $59-\mathrm{kD}$ protein (fibromodulin) is structurally related to the small interstitial proteoglycans PG-S1 and PG-S2 (decorin). EMBO Journal, 8: 2601-2604.

14. Weber IT, Harrison RW \& Iozzo RV (1996). Model structure of decorin and implications for collagen fibrillogenesis. Journal of Biological Chemistry, 71: 31767-31770.

15. Mow VC, Ratcliffe A \& Poole AR (1992). Cartilage and diarthrodial joints as paradigms for hierarchical materials and structures. Biomaterials, 13: 67-97

16. Thorp BH (1994). Skeletal disorders in the fowl: a review. Avian Pathology, 23: 203-236.

17. Heinegård D \& Sommarin $Y$ (1987). Isolation and characterization of proteoglycan. Methods in Enzymology, 144: 319-372.

18. Bradford MM (1976). A rapid and sensitive method for the quantification of microgram quantities of protein utilizing the principle of protein-dye binding. Analytical Biochemistry, 72: 248-254.

19. Farndale RW, Buttle PJ \& Barret AJ (1986). Improved quantitation and discrimination of sulphated glycosaminoglycans by use of dimethylmethylene blue. Biochimica et Biophysica Acta, 883: 173177.

20. Dische $Z$ (1947). A new specific color reaction of hexuronic acid. Journal of Biological Chemistry, 167: 189-199.

21. Saito H, Yamagata T \& Suzuki S (1968). Enzymatic methods for the determination of small quantities of isomeric chondroitin sulfates. Journal of Biological Chemistry, 243: 1536-1542.

22. Zingales B (1984). Analysis of protein sodium dodecyl sulfate-polyacrylamide gel electrophoresis. In: Morel CM (Editor), Genes and Antigens of Parasites. FIOCRUZ, Rio de aneiro, RJ, Brazil.

23. Blum B, Beier H \& Gross HJ (1987). Improved silver staining of plant proteins, RNA, and DNA in polyacrylamide gels. Electrophoresis, 8: 93-99.

24. Towbin T \& Gordon S (1979). Electrophoretic transfer of proteins from polyacrylamide gels to nitrocellulose sheets: procedures and some applications. Proceedings of the National Academy of Sciences, USA, 76: 4350-4354.

25. Dietrich CP \& Dietrich SMC (1976). Electrophoretic behaviour of acidic mucopolysaccharides in diamine buffers. Analytical Biochemistry, 70: 645-647
26. Beiguelman B (1991). Curso Prático de Bioestatística. 2nd edn. Editora São Paulo, São Paulo, SP, Brazil.

27. Lohmander S (1988). Proteoglycans of joint cartilage: structure, function turnover and role as markers of joint disease. Baillière's Clinical Rheumatology, 2: 37-62.

28. Anderson-Mackenzie JM, Hulmes DJ \& Thorp BH (1998). Effects of body mass and genotype on avian degenerative joint disease pathology and articular cartilage proteoglycan distribution. Clinical and Experimental Rheumatology, 16: 403-408.

29. Nakano T \& Sim JS (1995). A study of the chemical composition of the proximal tibial articular cartilage and growth plate of broiler chickens. Poultry Science, 74: 538-550.

30. Bjelle A, Gardell S \& Heinegård D (1974). Proteoglycans of articular cartilage from bovine lower femoral epiphysis. Extraction and characterization of proteoglycans from two sites within the same joint. Connective Tissue Research, 2: 111-116.

31. Swann DA, Powell S \& Sotman S (1979). The heterogeneity of cartilage proteoglycans. Isolation of different types of proteoglycans from bovine articular cartilage. Journal of Biological Chemistry, 254: 945-954

32. Manicourt DH, Pita JC, Pezon C \& Howell DS (1986). Characterization of the proteoglycan recovered under nondissociative conditions from normal articular cartilage of rabbits and dogs. Journal of Biological Chemistry, 261: 5426-5433.

33. Gomes L \& Pimentel ER (1994). Detection of a small proteoglycan present in xiphoid cartilage regions submitted to different biochemical forces. Brazilian Journal of Medical and Biological Research, 27 : 2117-2124.

34. Gomes L, Esquisatto MAM, Belline P \& Pimentel ER (1996). Is there a relationship between the state of aggregation of small proteoglycans and the biomechanical properties of tissues? Brazilian Journal of Medical and Biological Research, 29: 1243-1246.

35. Bidanset DJ, Guidry C, Rosemberg LC, Choi HU, Timpl R \& Hook M (1992). Binding of the proteoglycan decorin to collagen type II. Journal of Biological Chemistry, 267: 5250-5256.

36. Roughley PJ \& White RJ (1989). Dermatan sulphate proteoglycans of human articular cartilage. The properties of dermatan sulphate proteoglycan I and II. Biochemical Journal, 262: 823-827.

37. Cavalcante MCM, Mourão PAS \& Pavão MSG (1999). Isolation and characterization of a highly sulfated heparan sulfate from ascidians. Biochimica et Biophysica Acta, 1428: 77-87.

38. Imanari T, Toida T, Koshiishi I \& Toyoda H (1996). High-performance liquid chromatographic analysis of glycosaminoglycan-derived oligosaccharides. Journal of Chromatography. A, 720: 275-293.

39. Barnet $\mathrm{CH}$ (1954). A comparison of the human knee and avian ankle. Journal of Anatomy, 88: 59-70. 